\title{
Boron Carbon Nitride Thin Films: From Disordered to Ordered Conjugated Ternary Materials
}

\author{
Paolo Giusto,* Hiroki Arazoe, Daniel Cruz, Paola Lova, Tobias Heil, Takuzo Aida, \\ and Markus Antonietti
}

Cite This: J. Am. Chem. Soc. 2020, 142, 20883-20891

Read Online

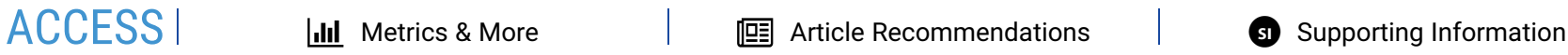

ABSTRACT: We present an innovative method for the synthesis of boron carbon nitride thin film materials in a simple furnace setup, using commonly available solid precursors and relatively low temperature compared to previous attempts. The as-prepared structural and optical properties of thin films are tuned via the precursor content, leading to a $\mathrm{sp}^{2}$-conjugated boron nitridecarbon nitride mixed material, instead of the commonly reported boron nitride-graphene phase segregation, with tunable optical properties such as band gap and fluorescence.

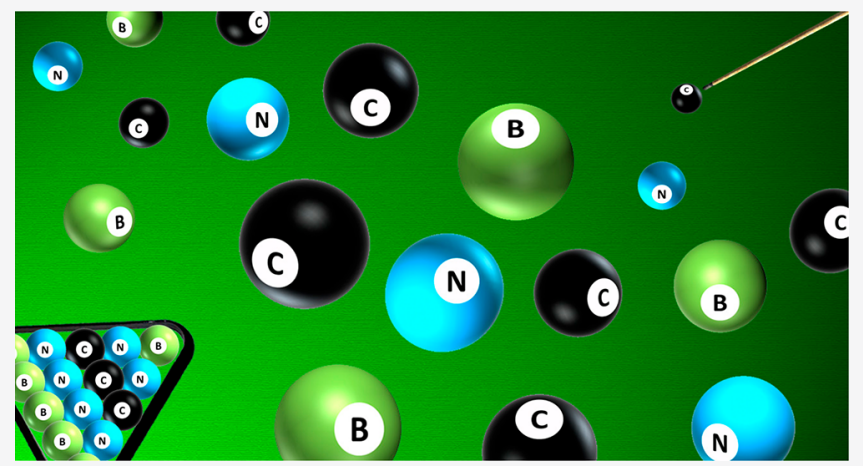

\section{INTRODUCTION}

Carbon is the sixth element of the periodic table and presumably the most important element of chemistry. The versatility of carbon is reflected in the countless numbers of molecules and materials based on this element reported to date. Elemental carbon is commonly found as graphite or diamond, and further tuning of the properties of these is achieved by elemental doping, introducing elements of similar size, like nitrogen and boron. The simultaneous introduction of boron and nitrogen atoms into carbon lattices opens a wide range of possibilities in terms of chemical structure and electronic and optical properties.

In the 20th century, with the development of modern analytical techniques, carbon chemistry has attracted even more and more attention. Many different carbon allotropes with different hybridizations $\left(\mathrm{sp}, \mathrm{sp}^{2}\right.$, and $\mathrm{sp}^{3}$ ) have been prepared and studied. These include HOPG (highly oriented pyrolytic graphite), fullerenes, carbon nanotubes, glassy carbons, and last but not least isolated 2D graphenes, which have attracted much interest because of their exceptional electronic, mechanical, and thermal properties.

Substitutional doping with heteroatoms into various carbon materials to replace carbon positions has been reported to even expand the property space. Among others, graphene, graphite, porous carbon, carbon nanotubes, and fullerenes were modified by substituting carbon with other nonmetallic elements such as boron, nitrogen, phosphorus, and sulfur, and many reports also describe codoping. ${ }^{2,3}$ Nitrogen doping seems to be remarkably simple and was proven to increase electrical conductivity by modification of the electronic structure. ${ }^{4-6}$ With appropriate nitrogen insertion in the carbon structure, the electron density at the Fermi level can be increased, the valence band lowered (more positive with respect to the standard hydrogen electrode), so the material becomes more stable upon oxidation. ${ }^{7}$ Increasing further the nitrogen content allows for creating a wide range of carbon- and nitrogen-based organic frameworks with tunable properties, of great interest for a wide range of applications, such as electrochemical energy storage and photoelectrocatalysis. ${ }^{8}$ The extreme of nitrogen introduction in a graphitic structure leads to carbon nitride $(\mathrm{CN})$, a mid band gap semiconductor with the ideal formula $\mathrm{C}_{3} \mathrm{~N}_{4}$, which has attracted much attention in the past decade, especially for photocatalysis and very recently also for optical and optoelectronic applications. ${ }^{9-15}$

Boron nitride $(\mathrm{BN})$ is isomorphous to graphene but very different from a physical and chemical properties point of view. For instance, the electronegativity difference between boron and nitrogen atoms leads to a localization of $\pi$ electrons on nitrogen atoms, thus creating an insulating material, with a band gap larger than $5 \mathrm{eV} .{ }^{16}$ The combination of boron, carbon, and nitrogen therefore can lead to a countless number of different materials and properties, from $\mathrm{CN}$ and $\mathrm{BN}$ to boron carbide (BC) and ternary boron carbon nitride $(\mathrm{BCN})$ compounds and from insulators to semiconductors and conductors. ${ }^{17,18}$

Received: October 16, 2020

Published: November 27, 2020 
Many attempts on the synthesis of BCN thin films have been reported, employing techniques such as ion-beam-assisted, pulsed laser deposition, radio frequency (RF)/direct current (DC) sputtering, and chemical vapor deposition (CVD) techniques, with a single-source precursor or different boron-, carbon-, and nitrogen-containing precursors. ${ }^{19}$ One of the first attempts to synthesize $\mathrm{BCN}$ thin films by chemical methods was reported by Kaner et al. in 1987. They used a mixture of three gaseous precursors, that is, boron trichloride, acetylene, and ammonia in the temperature range of $400-700{ }^{\circ} \mathrm{C} .{ }^{20}$ They found that boron, carbon, and nitrogen were successfully incorporated in the final material structure, showing XPS spectra different than the spectra of a mixture of graphite and $\mathrm{BN}$, proving in that way that all the elements were effectively incorporated into the material. More recently, inspired by synthetic methods of graphene, $\mathrm{Ci}$ et al. used a thermal catalytic method to deposit BCN thin film on a copper substrate from methane and ammonia-borane as gaseous coprecursors at 900-1000 ${ }^{\circ} \mathrm{C}$, leading to a demixed-island graphene-boron nitride composite with tunable band gap. ${ }^{21}$

We present here an innovative method for the synthesis of ternary BCN materials using melamine and boric acid as lowhazard solid precursors via vapor deposition polymerization on target substrates.

\section{RESULTS AND DISCUSSION}

As previously reported by Roy et al., melamine forms a cocrystal with boric acid by forming hydrogen-bonding network structure in the monoclinic system $P 2_{1} / c$, thus making it a possible singlesource precursor for ternary boron carbon nitride thin films deposition. ${ }^{22,23}$ Indeed, when a solution of boric acid is added to a melamine dispersion in water at $100^{\circ} \mathrm{C}$, gelation takes place by forming a cocrystal (Figure 1a). As shown in Fourier-transform infrared (FT-IR) spectra (Figure 1b), a broad absorption in the

$$
\text { a) }
$$
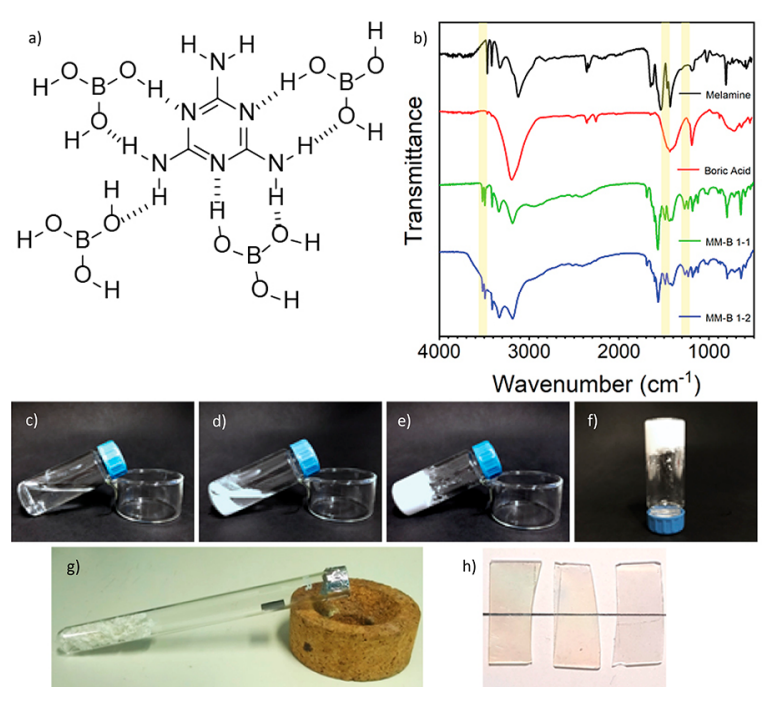

Figure 1. BCN thin film preparation. Melamine boric acid adduct (a) and FT-IR of the precursors and their mixture in different ratios (b); yellow bands highlight the major differences in the gel with respect to the precursors. Time lapse of the precursor preparation: boric acid dissolved in water at $100^{\circ} \mathrm{C}(\mathrm{c})$, melamine dispersed in water at $100{ }^{\circ} \mathrm{C}$ (d), and the melamine-boric acid adduct $(e-f)$. Test tube for the preparation of the thin films, with the dried precursor at the bottom and the substrate at the top $(\mathrm{g})$. From left to right: $\mathrm{CN}, \mathrm{BCN} 1-1$, and BCN 1-2 thin films on a glass substrate $(\mathrm{h})$.
$-\mathrm{OH}$ and $-\mathrm{NH}_{2}$ range $\left(3700-2700 \mathrm{~cm}^{-1}\right)$ shows that supramolecular hydrogen-bonded network formation has taken place. Furthermore, two new peaks at 3510 and 3490 $\mathrm{cm}^{-1}$ are attributed to $-\mathrm{NH}_{2}$ and $-\mathrm{OH}$ stretching. The activation of symmetric bending of the triazine ring at 1492 $\mathrm{cm}^{-1}$ and an appearance of new peaks of $\mathrm{B}-\mathrm{OH}$ bending in melamine diborate at 1231 and $1258 \mathrm{~cm}^{-1}$ is found after cocrystallization, indicating that melamine formed a hydrogenbonded network structure with boric acid. ${ }^{24,25}$ To deposit ternary $\mathrm{BCN}$ thin films, we used the vapor deposition polymerization method previously reported for the synthesis of carbon nitride materials. ${ }^{23,24}$ Briefly, the melamine-boric acid (MM-B) precursor, prepared with different molar ratios (i.e., 1$0,1-1$ and 1-2), is placed at the bottom of a glass test tube, with a target substrate toward the end and capped with holed aluminum foil (Figure 1c), and placed horizontally in a furnace. For the sake of clarity, the reference, which was synthesized without boric acid, that is, MM-B 1-0, will be named $\mathrm{CN}$ in the following. Indeed, melamine is an effective precursor for the deposition of $\mathrm{CN}$ thin films via chemical vapor deposition. ${ }^{9,26}$ The thin film deposition occurs via thermal degradation of the precursors and leads to very homogeneous ternary thin film coatings, with high transparency in the visible range (Figure 1d). The method allows for deposition of homogeneous crack-free thin films over large surfaces, above $2 \mathrm{~cm}^{2}$, with low surface roughness $\left(<10 \mathrm{~nm} \mathrm{Rq}\right.$, over areas $\left.>100 \mu \mathrm{m}^{2}\right)$, thus very close to the one of the bare glass substrate, as confirmed by atomic force microscopy (AFM) (Figure S1, Supporting Information). The low surface roughness is an important parameter for optical applications to avoid undesired scattering effects and keep high transparency in the visible range.

The surface homogeneity is also confirmed by scanning electron microscopy (SEM). The films appear quite homogeneous with only minor defects, thus making it difficult to say if the film is indeed deposited (Figure S2). To prove the presence of the ternary thin films, we analyzed the samples by energydispersive X-ray analysis (EDX) over different surface areas, which show the presence of carbon and nitrogen, for all samples, and boron, for BCN 1-1 and 1-2, as well as the signal coming from the substrate (Figure S2).

Transmission electron microscopy (TEM) provides additional information on the material nanostructure. The image from the $\mathrm{CN}$ (Figure 2a) shows the presence of a hexagonal diffraction pattern typical of carbon nitride materials, as previously reported. ${ }^{27}$ By introduction of boron into the precursor mixture, the nanostructure significantly changes to amorphous for $\mathrm{BCN} 1-1$ (Figure 2b), whereas a crystalline structure occurs for BCN 1-2 (Figure 2c). The latter, in particular, after masking the hexagonal spots from a selected area, reveals a diffraction pattern with an organized hexagonal structure (Figure $2 \mathrm{~d}$ ) with a periodic distance of about $0.208 \mathrm{~nm}$ (Figure S3), analogous to graphene $(0.214 \mathrm{~nm}){ }^{28,29}$ Furthermore, the fast Fourier transform (FFT) (Figure 2d, inset) of the magnified area shows that the layers are slightly displaced with a tilt of $13^{\circ}$ between the stacked planes, suggesting either a different composition in the $Z$-direction of the film or the involvement of non van der Waals interactions between the layers. $^{21}$ This effect is currently analyzed in more detail. The distortions are attributed to a slight lattice mismatch between two phases, which we can speculate are constituted of $\mathrm{B}-\mathrm{N}$-rich and $\mathrm{C}$-rich (or $\mathrm{C}-\mathrm{N}$-rich) areas. $^{28}$ It is worth pointing out that, in the present case, a highly organized ternary $\mathrm{BCN}$ structure has been obtained at relatively low temperature $\left(550{ }^{\circ} \mathrm{C}\right)$ and 

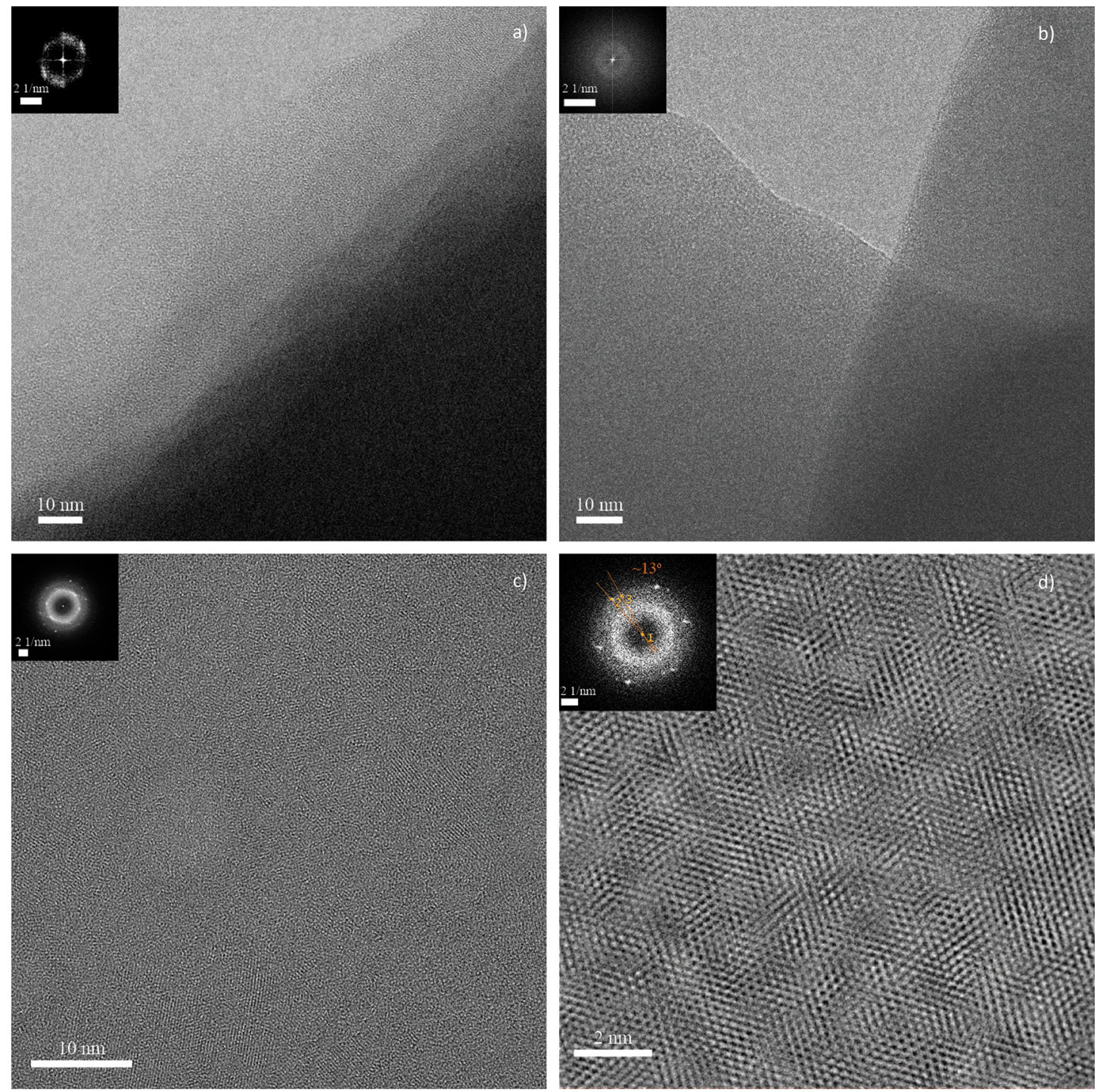

Figure 2. TEM images with FFT patterns as inserts of CN (a), BCN 1-1 (b), and BCN 1-2 (c) thin films. (d) shows a magnified area of (c) (FFTfiltered to emphasize the hexagonal structure).

without any catalytically active substrate, but on simple glass slides, in a test tube setup placed horizontally in a muffle furnace.

The boron concentration in the precursor strongly affects the structural properties, and thus also the optical properties, like optical band gap and photoluminescence, as it will be shown in the following. Nevertheless, increasing the amount of boron in the precursor leads also to different chemical composition and bonding, as quantified by electron energy loss spectroscopy (EELS) and X-ray photoelectron spectroscopy (XPS). EELS spectra (Figure 3a) confirm that the method successfully leads to deposition of the ternary boron-, carbon-, and nitrogencontaining thin film, both for BCN 1-1 and BCN 1-2, and only carbon and nitrogen for $\mathrm{CN}$. The $\mathrm{CN}$ thin films reveals also the presence of a conjugated system, with similar $1 \mathrm{~s} \rightarrow \pi^{*}$ and $1 \mathrm{~s}$ $\rightarrow \sigma^{*}$ peak intensity, both for carbon $(287 \mathrm{eV})$ and nitrogen $(400 \mathrm{eV})$ elements. Similar to that, the core-level EELS spectrum of the BCNs (1-1 and 1-2) thin film reveals that boron (at 193.5 and $193.75 \mathrm{eV}$ ), carbon (at 285 and $285.75 \mathrm{eV}$ ), and nitrogen (at 397.25 and $399.5 \mathrm{eV}$ ) K-edges show the presence of $1 \mathrm{~s} \rightarrow \pi^{*}$, confirming that $\mathrm{sp}^{2}$ conjugation is achieved throughout the sample, with only a minor contribution from oxygen at about $532 \mathrm{eV}$. The significant energy loss shift in the nitrogen $(2.25 \mathrm{eV})$ speaks for a higher level of oxidation of nitrogen in $\mathrm{BCN} 1-2$ with respect to $\mathrm{BCN} 1-1$, which can be attributed to better electron transfer to the boron via a more perfect aromatic condensation achieved. ${ }^{30}$ The degree of conjugation indeed increases for BCN 1-2, as reflected by the very prominent, extremely sharp $1 \mathrm{~s} \rightarrow \pi^{*}$ peaks, which are for boron, carbon, and nitrogen more intense than the respective $\sigma^{*}$ peak. (Figure 3a, red line). In all cases, the nearly identical Kedge structures of the atoms indicate a similar electronic environment of the constituting elements in the $\mathrm{BCN}$ and $\mathrm{CN}$ thin films.

To evaluate chemical bindings and relative composition occurring in $\mathrm{CN}$ and $\mathrm{BCN}$ materials, we analyzed the samples by XPS. The $\mathrm{CN}$ film shows the typical features of carbon nitride materials, with a major contribution from $-\mathrm{C}=\mathrm{N}-\mathrm{C}-$ triazinic groups and a $\mathrm{C} / \mathrm{N}$ of 0.71 , close to the ideal $\mathrm{g}-\mathrm{C}_{3} \mathrm{~N}_{4}(0.75)$ and in good agreement with previous results (Figure $3 \mathrm{~b}, \mathrm{c}$ ). ${ }^{10}$ Spectra of BCN 1-1 and 1-2 confirm once more the presence of the three elements in the sample (Figure $3 \mathrm{~d}-\mathrm{i}$ ). In both cases, the deconvolution of $\mathrm{C} 1 \mathrm{~s}$ and $\mathrm{N}$ 1s reveals a major contribution 

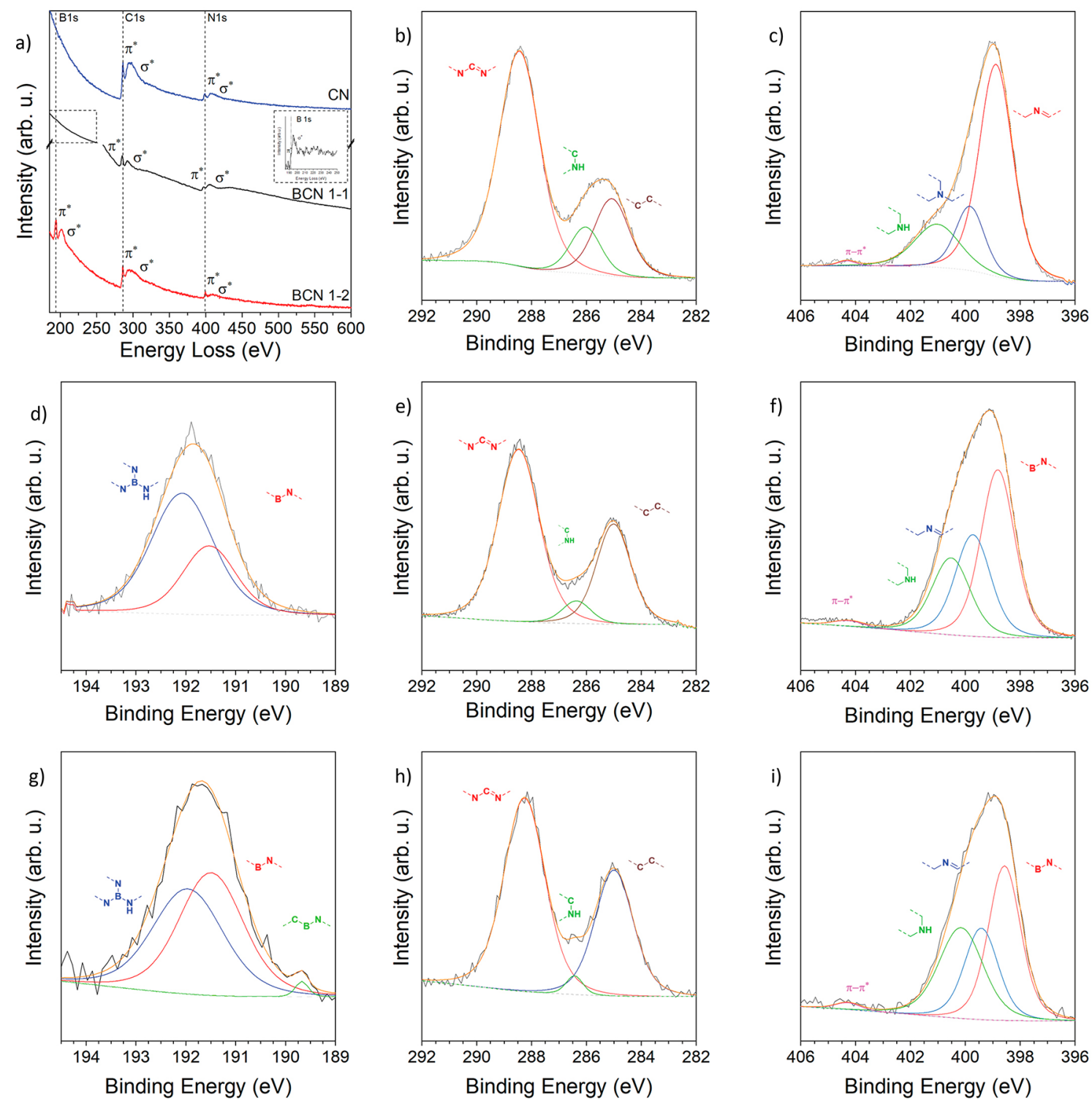

Figure 3. Elemental characterization of $\mathrm{CN}$ and $\mathrm{BCN}$ thin films. (a) EELS spectra of $\mathrm{CN}$ (blue line), $\mathrm{BCN} 1-1$ (black line), and $\mathrm{BCN}$ 1-2 (red line); the inset shows the background-corrected EELS spectrum in the boron energy loss range for BCN 1-1. XPS spectra of the following: $\mathrm{C}$ 1s (b) and N 1s (c) of CN films; B 1s (d), C 1s (e), and N 1s (f) of BCN 1-1 films; B 1s (g), C 1s (h), and N 1s (i) of BCN 1-2 films.

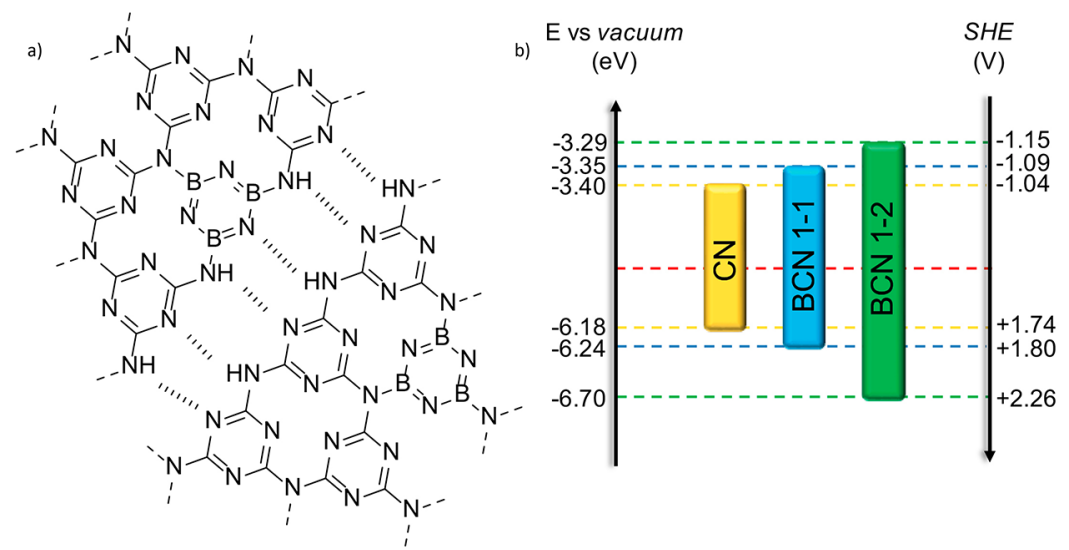

Figure 4. Chemical and electronic structure of $\mathrm{BCN}$ thin films. Proposed structure of the BCNs materials (a); energy levels of the thin films referred to vacuum and SHE (b). 
a)

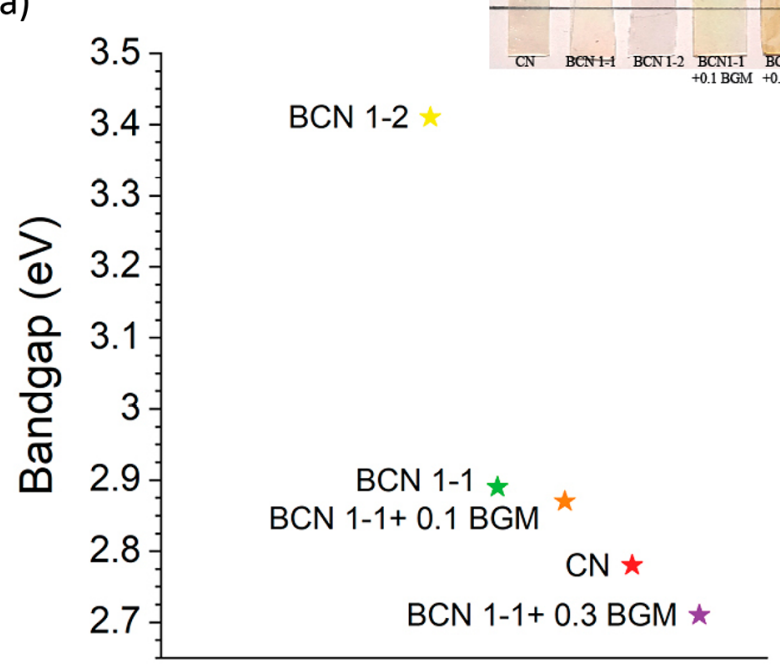

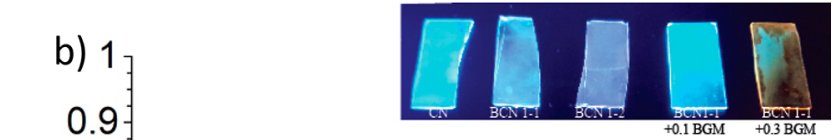

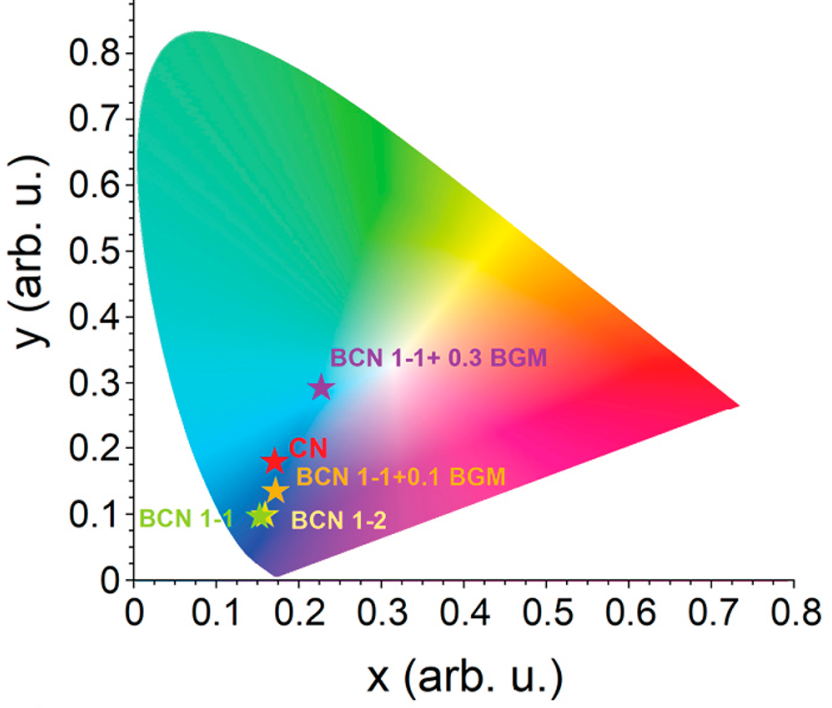

c)

\begin{tabular}{l|l|l|l} 
Sample & EQE (\%) & IQE $(\%)$ & PL lifetime (t1; t2) \\
\hline CN & 2.02 & 2.69 & $0.200 ; 33.4$ \\
\hline BCN 1-1 & 1.92 & 2.40 & $0.817 ; 62.89$ \\
\hline BCN 1-2 & 0.23 & 1.33 & - \\
\hline BCN 1-1+0.1 BGM & 3.46 & 4.07 & $2.14 ; 33.72$ \\
\hline BCN 1-1+0.3 BGM & 0.044 & 0.054 & $0.25 ; 1.10$
\end{tabular}

Figure 5. Optical properties of BCN materials. Optical band gap of the prepared thin films (a); fluorescence color of the thin films in CIE 1931 color scale (b); the inset shows the picture of the thin films under environmental light (a) and under UV illumination (b). Table listing the quantum yields (EQE and IQE) and photoluminescence (PL) lifetimes (c).

from $-\mathrm{N}-\mathrm{C}=\mathrm{N}-$ groups with a minor contribution from hydrogenated, terminal amino groups $(401 \mathrm{eV})$ and the $\pi-\pi^{*}$ shake-up satellite signal $(404.3 \mathrm{eV})$ (Figure $3 \mathrm{e}, \mathrm{f}, \mathrm{h}, \mathrm{i})$. The deconvolution of the $\mathrm{B} 1 \mathrm{~s}$ spectra shows for BCN 1-1 (Figure $3 \mathrm{~d})$ two main contributions, attributed to $\mathrm{H}-\mathrm{N}-\mathrm{B}-\mathrm{N}_{2}$ $(191.9-192.1 \mathrm{eV})$ and $\mathrm{sp}^{2} \mathrm{~B}-\mathrm{N}(191.5 \mathrm{eV})$ groups, and a minor contribution in the case of $\mathrm{BCN} 1-2$ (Figure $3 \mathrm{~g}$ ) of N-B$\mathrm{C}(189.6 \mathrm{eV})$ bondings. ${ }^{31,32}$ Surprisingly, no B-O bonds were detected in the XPS spectra, which usually occurs at $>193$ $\mathrm{eV} .^{31,33}$ Indeed, the deconvolution of $\mathrm{O} 1 \mathrm{~s}$ peaks reveals in all cases the presence of a single peak at $532.2 \mathrm{eV}$ that can be attributed to $\mathrm{Si}-\mathrm{O}$ (or $\mathrm{C}-\mathrm{O}$ ) bonds (Figure S4). ${ }^{33}$ The nitrogen peak is deconvoluted into four peaks corresponding to conjugated $-\mathrm{B}-\mathrm{N}-(398.6-398.8 \mathrm{eV}),-\mathrm{C}-\mathrm{N}=\mathrm{C}-(399.4-$ $399.7 \mathrm{eV})$, and $-\mathrm{N}-\mathrm{H}$ terminal groups $(400.2-400.5 \mathrm{eV})$ (Figure 3f,i). ${ }^{34}$ As previously shown for $\mathrm{CN}$, also in BCNs a shake-up satellite appears at $404.3 \mathrm{eV}$. The $\mathrm{C} 1 \mathrm{~s}$ deconvolution shows a major contribution of $-\mathrm{N}-\mathrm{C}=\mathrm{N}-$ groups $(288.5 \mathrm{eV})$ and only a minor signal related to terminal groups $(286.4 \mathrm{eV})$ (Figure 3e,h). XPS in general indicates more $\mathrm{B}-\mathrm{C}-\mathrm{N}$ mixed species than those in previously reported $\mathrm{B}-\mathrm{N} /$ graphene composites, and we relate that to the much lower synthesis temperature, stabilizing more sensitive phases.
Furthermore, from the analysis of the XPS spectra, we could derive the relative elemental composition $\mathrm{BC}_{3.6} \mathrm{~N}_{6}$ for $\mathrm{BCN}$ 1-1 (B/C/N ratio 9.4:34.0:56.6) and $\mathrm{BC}_{4} \mathrm{~N}_{6.3}$ for $\mathrm{BCN} 1-2(\mathrm{~B} / \mathrm{C} / \mathrm{N}$ ratio 8.9:35.3:55.8). The latter is of particular interest as it can be read as a $\mathrm{BN}$ structure surrounded by four $\mathrm{C}_{3} \mathrm{~N}_{4}$ units $\left(3\left(\mathrm{BC}_{4} \mathrm{~N}_{6.3}\right)=\mathrm{B}_{3} \mathrm{C}_{12} \mathrm{~N}_{19}=\mathrm{B}_{3} \mathrm{~N}_{3}+4 \mathrm{C}_{3} \mathrm{~N}_{4}\right)$, supporting the previous assumption of a structure constituted of $\mathrm{B}-\mathrm{N}$ units in a $\mathrm{C}-\mathrm{N}$ environment. This is also in good agreement with the XPS peak attribution. The model structures depicted below present possible chemical structures of the BCNs materials constituted of triazine and borazine units, cross-linked by hydrogen bonds (Figure 4a). We however believe that the present findings are only marked examples of a potentially very rich phase diagram of ternary BCN materials, which have been largely unexplored so far. These were chosen analogous to carbon nitride materials previously reported. ${ }^{35}$

The good optical quality of the BCN and CN thin films allow for application in optical and optoelectronic devices. In these regards, the tunability of the optical properties is of paramount importance. For instance, changing the band gap energy and the related strong optical absorption allows material with high transparency over the visible range. The elaboration of the absorption spectrum allows for defining optical band gap by the 
Tauc plot (Figure S5) of CN, BCN 1-1, and BCN 1-2, and HOMO-LUMO energy levels (Figure $4 \mathrm{~b}$ ) are accessible by means of ultraviolet photoelectron spectroscopy (Figure S5). At first glance, increasing the amount of boron widens the optical band gap from 2.78 for $\mathrm{CN}$ to 2.89 and $3.41 \mathrm{eV}$ for $\mathrm{BCN} 1-1$ and BCN 1-2, respectively. Contrary to doping, which introduces defect states within the band gap, the introduction of a significant amount of $\mathrm{BN}$ units into the $\mathrm{CN}$ lattice causes a widening of the band gap due to charge localization at the $\mathrm{BN}$ units, resulting in a redistribution of the $\pi$-states charges in the lattice. $^{36,37}$ Furthermore, the introduction of boron in the structure reduces the conduction band values with respect to $\mathrm{CN}$ (SHE, in V). This is also in good agreement with XPS spectra that show a larger amount of hydrogenated groups for BCN 1-1 with respect to BCN 1-2. The introduction of boron affects as such significantly the energy levels of the materials, which become more and more stable against oxidation in good agreement with previous results on BCN materials. ${ }^{38}$ Potential control of the HOMO/LUMO energy positions and the related possible band alignment in heterostructures is of paramount importance for implementing these materials in new generation carbon-based devices, here obtained from commonly available compounds and at relatively low temperature. For instance, the high transparency and the position of the LUMO levels of the BCNs make these materials of high interest as buffer/protection layers in solar cell devices. ${ }^{39}$

Other cases where the tunability of $\mathrm{BCN}$ materials could be of high interest is as photoelectro-catalysts, ${ }^{36,40,41}$ as well as in supercapacitors ${ }^{42-44}$ or for fluorescence. Recently, BCN dispersions of another type were embedded into a polymer matrix and used as phosphors with tunable luminescence spectra. ${ }^{19,34,45}$ However, for many applications, a homogeneous and insoluble thin film material is required, like in solar energy transducers, photoactive membranes, transistors and more. ${ }^{22,46}$ For this purpose, the BCN 1-1 synthesis was modified by the addition of $10 \%$ and $30 \%$ of a doping agent in the precursor mixture, namely, benzoguanamine (BGM), and labeled as BCN $1-1+0.1$ BGM and BCN 1-1 + 0.3 BGM, respectively. The introduction of benzoguanamine in the precursor allows for controlling the thin films optical band gap. As well-known from previous work, increasing the boron content in the precursor leads to widening of the band gap, from 2.78 for $\mathrm{CN}$ up to 3.41 $\mathrm{eV}$ for BCN 1-2 (Figure 4a). On the other hand, the addition of the doping agent causes a band gap shrinkage for the thin films of BCN 1-1 from 2.89 down to $2.71 \mathrm{eV}$ (Figure 5a, Tauc Plot in Figure S6). These tools allow also fluorescence emission to be tuned over a wider spectral range, from near UV up to the cyan range of the visible spectrum, as exemplarily shown in the CIE 1931 color space chromaticity diagram (Figure 5 b; fluorescence spectra and CIE 1931 X, Y Figure S7). BCN 1-2 thin films possess the lowest wavelength emission among all the films prepared and lying in the near-UV range $(386 \mathrm{~nm})$, in good agreement with the calculated band gaps, which is of particular interest in photonics or medicine as a black light source, which are usually made from gallium nitrides. ${ }^{20}$ On the opposite side, the longer wavelength emission is recorded for BCN 1-1+ 0.3 BGM with a maximum at $481 \mathrm{~nm}$ (Figure S7). The quantum yield and the fluorescence lifetimes (Figure 5c) reveal relatively low quantum yields (internal quantum yield, IQE; external quantum yield, EQE) and two fluorescence lifetimes (fluorescence lifetimes plot, fitting data, and equation in Figure S8). The fluorescence lifetimes reveal a very fast recombination process, below $3 \mathrm{~ns}$, and a second one, longer than $20 \mathrm{~ns}$, usually attributed to a long and rigid $\pi$-conjugated structure without rotatable bonds. ${ }^{47}$ The short fluorescence lifetime of BCN 1-1 $+0.3 \mathrm{BGM}$ is attributed to charge transfer to the doping agent functionalities introduced improving the nonradiative relaxation, as confirmed also by the very low quantum yield. This confirms our previous assumption that the material is composed of a distribution of different semiconducting domains with different band gaps, forming a heterojunction at the grain boundaries, facilitating charge transfer but spoiling luminescence. $^{48}$

\section{CONCLUSION}

In summary, we present an innovative method to prepare $\mathrm{BCN}$ thin films by the test tube method from a solid-state precursor at relatively low temperature in a simple and commonly available setup. The precursor is composed of common and lowhazardous chemicals boric acid and melamine. For one sample (BCN 1-2) we found a highly organized hexagonal structure with periodicities similar to the one of graphene. The asprepared thin films show energy levels and band gaps that are widely tunable, from the near-UV up to $460 \mathrm{~nm}$, with a similar trend also for photoluminescence emission. The engineering of the materials and optical properties allows these thin films to be potentially used in a wide range of applications, from UV absorbers over photochemistry up to interlayers in planar heterojunction-solar cells and electrochemical devices.

\section{MATERIALS AND METHODS}

Synthesis of the BCN 1-1 Precursor (MM-B 1-1). Melamine (1.26 g, Sigma-Aldrich, 99\%) and boric acid (0.62 g, ACROS Organics, $99.5 \%)$ were placed into two different glass vessels with 4 and $3 \mathrm{~mL}$ of deionized water, respectively. The two vessels were placed in an oil bath preheated at $95-100{ }^{\circ} \mathrm{C}$ and stirred until boric acid completely dissolved. When the boric acid was completely dissolved, to this solution was added the warm melamine dispersion, which promptly created a white solid precipitate. The precipitate was dried for 30-40 $\mathrm{min}$ in an oil bath and then it was allowed to further dry in a vacuum oven at $40^{\circ} \mathrm{C}$, overnight.

Synthesis of the BCN 1-2 Precursor (MM-B 1-2). Melamine (1.26 g, Sigma-Aldrich, 99\%) and boric acid (1.24 g, ACROS Organics, 99.5\%) were placed into two different glass vessels with 4 and $6 \mathrm{~mL}$ of deionized water, respectively. The two vessels were placed in an oil bath preheated at $95-100{ }^{\circ} \mathrm{C}$ and stirred, until boric acid completely dissolved. When the boric acid was completely dissolved, to this solution was added the warm melamine dispersion, which promptly created a white solid precipitate. The precipitate was further dried for $30-40 \mathrm{~min}$ in an oil bath and then it was allowed to further dry in a vacuum oven at $40^{\circ} \mathrm{C}$, overnight.

Synthesis of CN Thin Films. In a typical recipe, $1 \mathrm{~g}$ of melamine (Sigma-Aldrich, 99\%) was placed at the bottom of an $18 \mathrm{~cm}$ test tube $(18 \mathrm{~mm}$ diameter $)$. A glass slide $(1 \times 2.5 \mathrm{~cm})$ was then inserted at the top of the test tube and placed at about $3 \mathrm{~cm}$ from the top. Then the test tube was capped with an aluminum foil lid with holes and placed horizontally into a muffle furnace. Under $\mathrm{N}_{2}$ flow the temperature was increased to $300{ }^{\circ} \mathrm{C}$ at $10{ }^{\circ} \mathrm{C} / \mathrm{min}$ and kept for $30 \mathrm{~min}$ and then the temperature was further increased to $550^{\circ} \mathrm{C}$ at $2.5^{\circ} \mathrm{C} / \mathrm{min}$ and kept for $4 \mathrm{~h}$. After the deposition program was finished, it was allowed to cool down naturally and the sample was collected when it reached room temperature.

Synthesis of BCN 1-1 Thin Films. In a typical recipe, $1.8 \mathrm{~g}$ of $\mathrm{BCN}$ 1-1 precursor was placed at the bottom of an $18 \mathrm{~cm}$ test tube $(18 \mathrm{~mm}$ diameter). A glass slide $(1 \times 2.5 \mathrm{~cm})$ was then inserted at the top of the test tube and placed at about $3 \mathrm{~cm}$ from the top. Then the test tube was capped with an aluminum foil lid with holes and placed horizontally into a muffle furnace. Under $\mathrm{N}_{2}$ flow the temperature was increased to $300^{\circ} \mathrm{C}$ at $10^{\circ} \mathrm{C} / \mathrm{min}$ and kept for $30 \mathrm{~min}$ and then the temperature was 
further increased to $550{ }^{\circ} \mathrm{C}$ at $2.5^{\circ} \mathrm{C} / \mathrm{min}$ and kept for $4 \mathrm{~h}$. After the deposition program was finished, it was allowed to cool down naturally and the sample was collected when it reached room temperature.

Synthesis of BCN 1-2 Thin Films. In a typical recipe, $2.4 \mathrm{~g}$ of BCN 1-2 precursor was placed at the bottom of an $18 \mathrm{~cm}$ test tube $(18 \mathrm{~mm}$ diameter). A glass slide $(1 \mathrm{~cm}$ times $2.5 \mathrm{~cm}$ ) was then inserted at the top of the test tube and placed at about $3 \mathrm{~cm}$ from the top. Then the test tube was capped with an aluminum foil lid with holes and placed horizontally into a muffle furnace. Under $\mathrm{N}_{2}$ flow the temperature was increased to $300{ }^{\circ} \mathrm{C}$ at $10^{\circ} \mathrm{C} / \mathrm{min}$ and kept for $30 \mathrm{~min}$ and then the temperature was further increased to $550^{\circ} \mathrm{C}$ at $2.5^{\circ} \mathrm{C} / \mathrm{min}$ and kept for $4 \mathrm{~h}$. After the deposition program was finished, it was allowed to cool down naturally and the sample was collected when it reached room temperature.

Scanning Electron Microscopy and Energy-Dispersive X-ray Spectroscopy. SEM imaging was performed after $\mathrm{Au} / \mathrm{Pd}$ sputtering of the sample on carbon sample holders in a Zeiss LEO 1550-Gemini system (acceleration voltage: 3-10 kV) equipped with an Oxford Instruments X-MAX $80 \mathrm{~mm}^{2}$ detector, which was used to collect the SEM-EDX data.

Transmission Electron Microscopy and Electron Energy Loss Spectroscopy. The measurements were acquired using a double-Cscorrected JEOL JEM-ARM200F microscope, equipped with a cold field emission gun, a Gatan GIF Quantum detector, and a JED-2300 energydispersive X-ray detector. The acceleration voltage was typically set to $80-200 \mathrm{kV}$.

X-ray Photoelectron Spectroscopy and Ultraviolet Photoelectron Spectroscopy. XPS measurements were performed using CISSY equipment with a SPECS XR $50 \mathrm{X}$-ray gun $\mathrm{Mg} \mathrm{K} \alpha$ radiation $(1254.6 \mathrm{eV})$ and Combined Lens Analyzer Module (CLAM) in an ultrahigh vacuum chamber. In the same chamber were collected UPS spectra by SPECS UVS 10/35, which was used with a He I (21.2 eV) radiation source. The detector was a CombinedLens with an analyzer module thermoVG (TLAM). The Fermi level of gold reference was used to calibrate the system.

Fourier Transform Infrared Spectroscopy. FT-IR spectra were collected in the range $4000-500 \mathrm{~cm}^{-1}$ with a Thermo Scientific Nicolet iD5 spectrometer with an attenuated total reflection support.

Fluorescence Spectroscopy. Photoluminescence spectra were recorded by a Horiba FluoroMax-4 equipped with a thin film sample holder set at $60^{\circ}$ with respect to the excitation, integration time $0.2-1 \mathrm{~s}$, and slits apertures 1 . All the fluorescence spectra were recorded using excitation at $350 \mathrm{~nm}$.

Atomic Force Microscopy. AFM surface patterns were obtained with a Dimension 3100 Atomic Force Microscopy from Veeco Instruments.

External and Internal Fluorescence Quantum Yield. Fluorescence Quantum yields were by a Jasco FP-8300 spectrofluoremeter with excitation at $370 \mathrm{~nm}$ and equipped with an integration sphere by measuring direct and indirect excitation of each sample.

Time-Correlated Single Photon Counting. The fluorescence decays lifetimes were obtained by using a $405 \mathrm{~nm}$ pulsed excitation LDH-P-C-405 laser combined with a PDL $800 \mathrm{~B}$ driver and a PicoQuant Time Correlated Single Photon Counting system (Time Harp 260 PICO board, 200 ps pulse).

Absorbance Spectroscopy. Absorbance spectra were obtained by a Shimadzu UV 2600 equipped with an integrating sphere.

\section{ASSOCIATED CONTENT}

\section{s) Supporting Information}

The Supporting Information is available free of charge at https://pubs.acs.org/doi/10.1021/jacs.0c10945.

Supporting figures and tables, AFM and SEM images of the $\mathrm{CN}$ and $\mathrm{BCN}$ thin films, XPS, UPS, Tauc plots, TCSPC, and fluorescence spectra of $\mathrm{CN}$ and BCN thin films. Additional FFT and TEM elaboration of BCN 1-2 films (PDF)

\section{AUTHOR INFORMATION}

\section{Corresponding Author}

Paolo Giusto - Department of Colloid Chemistry, Max Planck Institute of Colloids and Interfaces, Potsdam 14476, Germany; 이이.org/0000-0003-4181-6500; Email: Paolo.Giusto@mpikg.mpg.de

\section{Authors}

Hiroki Arazoe - Department of Chemistry and Biotechnology, University of Tokyo, Tokyo 113-0033, Japan

Daniel Cruz - Department of Inorganic Chemistry, FritzHaber-Institut der Max-Planck-Gesellschaft, Berlin 14195, Germany; Department of Heterogeneous Reactions, MaxPlanck-Institut für Chemische Energiekonversion, Mülheim 45470, Germany

Paola Lova - Dipartimento di Chimica e Chimica Industriale, Universita degli Studi di Genova, Genova 16146, Italy; (i) orcid.org/0000-0002-5634-6321

Tobias Heil - Department of Colloid Chemistry, Max Planck Institute of Colloids and Interfaces, Potsdam 14476, Germany

Takuzo Aida - Department of Chemistry and Biotechnology, University of Tokyo, Tokyo 113-0033, Japan; 이이.org/ 0000-0002-0002-8017

Markus Antonietti - Department of Colloid Chemistry, Max Planck Institute of Colloids and Interfaces, Potsdam 14476, Germany

Complete contact information is available at:

https://pubs.acs.org/10.1021/jacs.0c10945

\section{Notes}

The authors declare no competing financial interest.

\section{ACKNOWLEDGMENTS}

The authors thank the Max Planck Gesellschaft for funding, Reinhild Dünnebacke for AFM measurements, Heike Runge for SEM and EDX measurements, Prof. Marc Georg Willinger for TEM measurements, Prof. Davide Comoretto for discussion and TCSPC setup, Dr. Iver Lauermann for XPS and UPS setup, Dr. Oleksandr Savateev for absorbance and quantum yield optical setup. Dr. Majd Al-Naji, Dr. Baris Kumru, Francesco Brandi, and Regina Rothe for their help during the project development and fruitful discussion. P.G. wants to dedicate this paper to the memory of Prof. Sergio Thea.

\section{REFERENCES}

(1) Dresselhaus, M. S.; Terrones, M. Carbon-based nanomaterials from a historical perspective. Proc. IEEE 2013, 101 (7), 1522-1535.

(2) Inagaki, M.; Toyoda, M.; Soneda, Y.; Morishita, T. Nitrogendoped carbon materials. Carbon 2018, 132, 104-140.

(3) Fechler, N.; Fellinger, T.-P.; Antonietti, M. One-pot synthesis of nitrogen-sulfur-co-doped carbons with tunable composition using a simple isothiocyanate ionic liquid. J. Mater. Chem. A 2013, 1 (45), 14097-14102.

(4) Burch, H. J.; Davies, J. A.; Brown, E.; Hao, L.; Contera, S. A.; Grobert, N.; Ryan, J. Electrical conductance and breakdown in individual $\mathrm{CN} x$ multiwalled nanotubes. Appl. Phys. Lett. 2006, 89 (14), 143110.

(5) Czerw, R.; Terrones, M.; Charlier, J.-C.; Blase, X.; Foley, B.; Kamalakaran, R.; Grobert, N.; Terrones, H.; Tekleab, D.; Ajayan, P.; et al. Identification of electron donor states in $\mathrm{N}$-doped carbon nanotubes. Nano Lett. 2001, 1 (9), 457-460.

(6) Brandi, F.; Bäumel, M.; Molinari, V.; Shekova, I.; Lauermann, I.; Heil, T.; Antonietti, M.; Al-Naji, M. Nickel on nitrogen-doped carbon 
pellets for continuous-flow hydrogenation of biomass-derived compounds in water. Green Chem. 2020, 22 (9), 2755-2766.

(7) Walczak, R.; Kurpil, B.; Savateev, A.; Heil, T.; Schmidt, J.; Qin, Q.; Antonietti, M.; Oschatz, M. Template-and Metal-Free Synthesis of Nitrogen-Rich Nanoporous "Noble" Carbon Materials by Direct Pyrolysis of a Preorganized Hexaazatriphenylene Precursor. Angew. Chem., Int. Ed. 2018, 57 (33), 10765-10770.

(8) Sakaushi, K.; Antonietti, M. Carbon- and Nitrogen-Based Organic Frameworks. Acc. Chem. Res. 2015, 48 (6), 1591-1600.

(9) Giusto, P.; Cruz, D.; Heil, T.; Arazoe, H.; Lova, P.; Aida, T.; Comoretto, D.; Patrini, M.; Antonietti, M. Shine Bright Like a Diamond: New Light on an Old Polymeric Semiconductor. Adv. Mater. 2020, 32, 1908140.

(10) Wang, X.; Maeda, K.; Thomas, A.; Takanabe, K.; Xin, G.; Carlsson, J. M.; Domen, K.; Antonietti, M. A metal-free polymeric photocatalyst for hydrogen production from water under visible light. Nat. Mater. 2009, 8 (1), 76.

(11) Bian, J.; Huang, C.; Zhang, R. Q. Graphitic carbon nitride film: an emerging star for catalytic and optoelectronic applications. ChemSusChem 2016, 9 (19), 2723-2735.

(12) Liu, J.; Wang, H.; Antonietti, M. Graphitic carbon nitride "reloaded": emerging applications beyond (photo) catalysis. Chem. Soc. Rev. 2016, 45 (8), 2308-2326.

(13) Xu, J.; Shalom, M.; Piersimoni, F.; Antonietti, M.; Neher, D.; Brenner, T. J. Color-Tunable Photoluminescence and NIR Electroluminescence in Carbon Nitride Thin Films and Light-Emitting Diodes. Adv. Opt. Mater. 2015, 3 (7), 913-917.

(14) Kumru, B.; Antonietti, M. Colloidal properties of the metal-free semiconductor graphitic carbon nitride. Adv. Colloid Interface Sci. 2020 283, 102229.

(15) Mazzanti, S.; Kurpil, B.; Pieber, B.; Antonietti, M.; Savateev, A. Dichloromethylation of enones by carbon nitride photocatalysis. Nat. Commun. 2020, 11 (1), 1387.

(16) Zeng, H.; Zhi, C.; Zhang, Z.; Wei, X.; Wang, X.; Guo, W.; Bando, Y.; Golberg, D. White graphenes": boron nitride nanoribbons via boron nitride nanotube unwrapping. Nano Lett. 2010, 10 (12), 5049-5055.

(17) Miyamoto, Y.; Rubio, A.; Cohen, M. L.; Louie, S. G. Chiral tubules of hexagonal BC 2 N. Phys. Rev. B: Condens. Matter Mater. Phys. 1994, 50 (7), 4976.

(18) Lu, J.; Zhang, K.; Liu, X. L.; Zhang, H.; Sum, T. C.; Castro Neto, A. H.; Loh, K. P. Order-disorder transition in a two-dimensional boron-carbon-nitride alloy. Nat. Commun. 2013, 4, 2681.

(19) Song, L.; Liu, Z.; Reddy, A. L. M.; Narayanan, N. T.; TahaTijerina, J.; Peng, J.; Gao, G.; Lou, J.; Vajtai, R.; Ajayan, P. M. Binary and ternary atomic layers built from carbon, boron, and nitrogen. $A d v$. Mater. 2012, 24 (36), 4878-4895.

(20) Kaner, R.; Kouvetakis, J.; Warble, C.; Sattler, M.; Bartlett, N. Boron-carbon-nitrogen materials of graphite-like structure. Mater. Res. Bull. 1987, 22 (3), 399-404.

(21) Ci, L.; Song, L.; Jin, C.; Jariwala, D.; Wu, D.; Li, Y.; Srivastava, A.; Wang, Z.; Storr, K.; Balicas, L.; et al. Atomic layers of hybridized boron nitride and graphene domains. Nat. Mater. 2010, 9 (5), 430.

(22) Roy, A.; Choudhury, A.; Rao, C. N. R. Supramolecular hydrogenbonded structure of a 1:2 adduct of melamine with boric acid. J. Mol. Struct. 2002, 613 (1-3), 61-66.

(23) Kawasaki, T.; Kuroda, Y.; Nishikawa, H. The crystal structure of melamine diborate. Nippon Seramikkusu Kyokai Gakujutsu Ronbunshi 1996, 104 (1214), 935-938.

(24) Panicker, C. Y.; Varghese, H. T.; John, A.; Philip, D.; Nogueira, H. I. Vibrational spectra of melamine diborate, C3N6H62H3BO3. Spectrochim. Acta, Part A 2002, 58 (8), 1545-1551.

(25) Wu, C.; Wang, B.; Wu, N.; Han, C.; Zhang, X.; Shen, S.; Tian, Q.; Qin, C.; Li, P.; Wang, Y. Molecular-scale understanding on the structure evolution from melamine diborate supramolecule to boron nitride fibers. Ceram. Int. 2020, 46 (1), 1083-1090.

(26) Giusto, P.; Kumru, B.; Zhang, J.; Rothe, R.; Antonietti, M. Let a hundred polymers bloom: tunable wetting of photografted polymercarbon nitride surfaces. Chem. Mater. 2020, 32 (17), 7284-7291.
(27) Wen, J.; Xie, J.; Chen, X.; Li, X. A review on g-C3N4-based photocatalysts. Appl. Surf. Sci. 2017, 391, 72-123.

(28) Lee, K. H.; Park, H.; Eom, W.; Kang, D. J.; Noh, S. H.; Han, T. H. Graphene quantum dots/graphene fiber nanochannels for osmotic power generation. J. Mater. Chem. A 2019, 7 (41), 23727-23732.

(29) Li, B.; Nan, Y.; Zhang, P.; Song, X. Structural characterization of individual graphene sheets formed by arc discharge and their growth mechanisms. RSC Adv. 2016, 6 (24), 19797-19806.

(30) Otten, M. T.; Miner, B.; Rask, J. H.; Buseck, P. R. The determination of $\mathrm{Ti}, \mathrm{Mn}$ and $\mathrm{Fe}$ oxidation states in minerals by electron energy-loss spectroscopy. Ultramicroscopy 1985, 18 (1-4), 285-289.

(31) Matsoso, B. J.; Ranganathan, K.; Mutuma, B. K.; Lerotholi, T.; Jones, G.; Coville, N. J. Single-step synthesis of crystalline h-BN quantum-and nanodots embedded in boron carbon nitride films. Nanotechnology 2017, 28 (10), 105602.

(32) Wang, W.; Zhou, H.; Liu, Y.; Zhang, S.; Zhang, Y.; Wang, G.; Zhang, H.; Zhao, H. Formation of $\mathrm{B} \square \mathrm{N} \square \mathrm{C}$ Coordination to Stabilize the Exposed Active Nitrogen Atoms in g-C3N4 for Dramatically Enhanced Photocatalytic Ammonia Synthesis Performance. Small 2020, 16 (13), 1906880.

(33) Naumkin, A. V.; Kraut-Vass, A.; Gaarenstroom, S. W.; Powell, C. J. NIST X-ray photoelectron spectroscopy database. NIST standard reference database 20, version 4.1. U.S. Department of Commerce, Washington, DC, 2012.

(34) Lei, W.; Portehault, D.; Dimova, R.; Antonietti, M. Boron carbon nitride nanostructures from salt melts: tunable water-soluble phosphors. J. Am. Chem. Soc. 2011, 133 (18), 7121-7127.

(35) Arazoe, H.; Miyajima, D.; Akaike, K.; Araoka, F.; Sato, E.; Hikima, T.; Kawamoto, M.; Aida, T. An autonomous actuator driven by fluctuations in ambient humidity. Nat. Mater. 2016, 15 (10), 1084.

(36) Wang, Y.; Zhang, J.; Wang, X.; Antonietti, M.; Li, H. Boron- and Fluorine-Containing Mesoporous Carbon Nitride Polymers: MetalFree Catalysts for Cyclohexane Oxidation. Angew. Chem., Int. Ed. 2010, 49 (19), 3356-3359.

(37) Fan, X.; Shen, Z.; Liu, A.; Kuo, J.-L. Band gap opening of graphene by doping small boron nitride domains. Nanoscale 2012, 4 (6), 2157-2165.

(38) Zhou, M.; Wang, S.; Yang, P.; Huang, C.; Wang, X. Boron Carbon Nitride Semiconductors Decorated with CdS Nanoparticles for Photocatalytic Reduction of CO2. ACS Catal. 2018, 8 (6), 4928-4936.

(39) Cruz, D.; Garcia Cerrillo, J.; Kumru, B.; Li, N.; Dario Perea, J.; Schmidt, B. V.; Lauermann, I.; Brabec, C. J.; Antonietti, M. Influence of Thiazole-Modified Carbon Nitride Nanosheets with Feasible Electronic Properties on Inverted Perovskite Solar Cells. J. Am. Chem. Soc. 2019, 141 (31), 12322-12328.

(40) Chen, L.; Zhou, M.; Luo, Z.; Wakeel, M.; Asiri, A. M.; Wang, X. Template-free synthesis of carbon-doped boron nitride nanosheets for enhanced photocatalytic hydrogen evolution. Appl. Catal., B 2019, 241, 246-255.

(41) Huang, C.; Chen, C.; Zhang, M.; Lin, L.; Ye, X.; Lin, S.; Antonietti, M.; Wang, X. Carbon-doped BN nanosheets for metal-free photoredox catalysis. Nat. Commun. 2015, 6, 7698.

(42) Ghosh, I.; Khamrai, J.; Savateev, A.; Shlapakov, N.; Antonietti, M.; König, B. Organic semiconductor photocatalyst can bifunctionalize arenes and heteroarenes. Science 2019, 365 (6451), 360-366.

(43) Wang, J.; Hao, J.; Liu, D.; Qin, S.; Portehault, D.; Li, Y.; Chen, Y.; Lei, W. Porous boron carbon nitride nanosheets as efficient metal-free catalysts for the oxygen reduction reaction in both alkaline and acidic solutions. ACS Energy Letters 2017, 2 (2), 306-312.

(44) Ling, Z.; Wang, Z.; Zhang, M.; Yu, C.; Wang, G.; Dong, Y.; Liu, S.; Wang, Y.; Qiu, J. Sustainable synthesis and assembly of biomassderived $\mathrm{B} / \mathrm{N}$ co-doped carbon nanosheets with ultrahigh aspect ratio for high-performance supercapacitors. Adv. Funct. Mater. 2016, 26 (1), 111-119.

(45) Wang, W.-N.; Ogi, T.; Kaihatsu, Y.; Iskandar, F.; Okuyama, K. Novel rare-earth-free tunable-color-emitting BCNO phosphors. J. Mater. Chem. 2011, 21 (14), 5183-5189.

(46) Xiao, K.; Giusto, P.; Wen, L.; Jiang, L.; Antonietti, M. Nanofluidic Ion Transport and Energy Conversion through Ultrathin 
Free-Standing Polymeric Carbon Nitride Membranes. Angew. Chem. 2018, 130 (32), 10280-10283.

(47) Berezin, M. Y.; Achilefu, S. Fluorescence lifetime measurements and biological imaging. Chem. Rev. 2010, 110 (5), 2641-2684.

(48) Shalom, M.; Guttentag, M.; Fettkenhauer, C.; Inal, S.; Neher, D.; Llobet, A.; Antonietti, M. In situ formation of heterojunctions in modified graphitic carbon nitride: Synthesis and noble metal free photocatalysis. Chem. Mater. 2014, 26 (19), 5812-5818. 